\title{
Multistage remediation of heavy metal contaminated river sediments in a mining region based on particle size
}

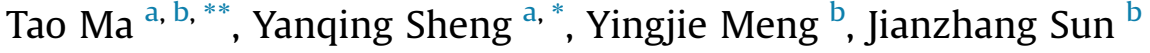 \\ ${ }^{a}$ Research Center for Coastal Environment Engineering Technology of Shandong Province, Yantai Institute of Coastal Zone Research, Chinese Academy of \\ Sciences, Yantai, 264000, PR China \\ ${ }^{\mathrm{b}}$ Shandong Academy of Environmental Science Co., LTD., Jinan, 250100, PR China
}

\section{H I G H L I G H T S}

- Non-residual fraction heavy metals in sediments reserved in fine particles.

- Washing transformed heavy metals from large particles to fine ones.

- Feasibility of multistage remediation was proved by field work.

\section{A R T I C L E I N F O}

\section{Article history:}

Received 1 January 2019

Received in revised form

27 February 2019

Accepted 4 March 2019

Available online 6 March 2019

Handling Editor: X. Cao

\section{Keywords:}

Particle size

Heavy metal

Sediment

Classification treatment

Mining area

\section{G R A P H I C A L A B S T R A C T}

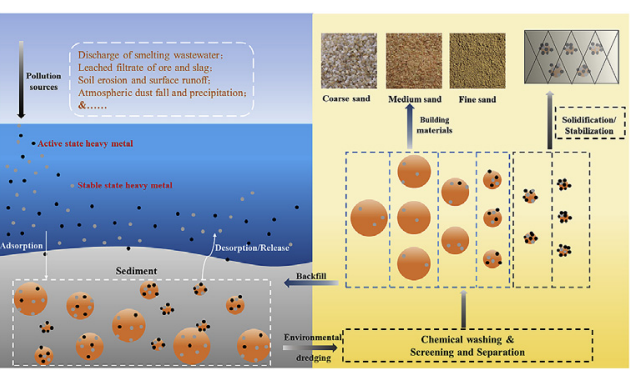

\begin{abstract}
A B S T R A C T
Sediment pollution is an important environmental problem, and the remediation of heavy metal contaminated sediments is crucial to river ecosystem protection, especially in mining regions. In this work, characteristics of heavy metals $(\mathrm{Cu}, \mathrm{Zn}, \mathrm{Cd}, \mathrm{As}$ and $\mathrm{Hg}$ ) were investigated, including contents and fractions based on particle size (PS) in river sediments. Chemical leaching and stabilization for sediment remediation were performed, and the technology feasibility was assessed. The results indicated that the heavy metals were primarily reserved within fine sediments (PS $<75 \mu \mathrm{m}$ ), comprising $79.8 \%$ of the total. For the sequentially extracted fractions, residual fraction dominated the total content in large PS sections (PS $>150 \mu \mathrm{m}$ ), while the oxidizable fraction, reducible fraction and weak acid extractable fraction dominated the total content in fine sediments, except for that of Hg. Chemical leaching can transform most metals in sediments from large-sized particles to fine particles because the metals are absorbed by fine particles in solution rather than complexation. The stabilization suggested that cement could be an effective agent for ecological risk control for heavy metals. In field engineering, a total of $145,000 \mathrm{~m}^{3}$ sediment was divided into various sections by PS and synchronously washed by eluting agents. Finally, clean sediments (PS $>150 \mu \mathrm{m}$ ) were used as building material and clean backfilling; meanwhile, heavily polluted sediments (PS $<150 \mu \mathrm{m}$ ) were buried as general industrial solid waste after stabilization treatment. Over $90 \%$ of the contaminated sediments were reused throughout multistep remediation. Furthermore, a reduction in waste and harm, along with resources, was obtained. This study provided a feasible technology for heavy metal contaminated sediment remediation.
\end{abstract}

๑ 2019 Elsevier Ltd. All rights reserved.

\footnotetext{
* Corresponding author.

** Corresponding author. Research Center for Coastal Environment Engineering Technology of Shandong Province, Yantai Institute of Coastal Zone Research, Chinese Academy of Sciences, Yantai, 264000, PR China.

E-mail address: yqsheng@yic.ac.cn (Y. Sheng).
} 


\section{Introduction}

Sediment is an important component in aquatic ecosystems in because it can absorb pollutants from overlying water to improve water quality and provide habitat and food source for benthic organisms. However, with rapid economic development and population growth, sediment heavy metal contamination in rivers/lakes has become a serious problem worldwide (Lin et al., 2016; Sindern et al., 2016; Villanueva et al., 2013; Xia et al., 2018; Zhao et al., 2017). Generally, heavy metals in sediment could be released into overlying water under some conditions and endanger the aquatic environment, resulting in toxicity to benthic organisms (Goretti et al., 2016). Once the heavy metal enters the food web, it can be released and accumulated in biological organisms, ultimately endangering human health (Chowdhury et al., 2016). Therefore, heavy metal contaminated sediments in aquatic ecosystems should be remediated in a timely fashion.

Although there are many methods for heavy metal contaminated sediment remediation, in situ and ex situ remediation are popular techniques (Khan et al., 2004). In situ remediation aims to increase the stabilization of metal in sediment particles by techniques including capping, immobilization, microbial degradation, phytoremediation and functional adsorption materials (Liu et al., 2018b; Song et al., 2017). The ecological risk and cost of in situ remediation are relatively low due to its simple operation. However, a potential secondary pollution source evidently exists in the ecosystem, because the total content of heavy metals in sediment remains unchanged (Liu et al., 2018a). Ex situ remediation focuses on extracting or separating heavy metals from sediment after dredging (Begum et al., 2012; Sun et al., 2001). These methods could greatly reduce the heavy metals within sediment directly based on metal characteristics (e.g., grain size fractions, physical and chemical properties) and stabilize the residual. As a potential ex situ remediation technique for heavy metal pollution, multistage remediation is feasible for its effective removal of $\mathrm{As}, \mathrm{Cd}, \mathrm{Pb}$, and $\mathrm{Zn}$ in soil by combined sieving and washing process (Li et al., 2019). During washing process, $\mathrm{Cd}, \mathrm{Cu}, \mathrm{Pb}$ and $\mathrm{Zn}$ in dredged sediment can be removed by chelating agents (Polettini et al., 2006). Due to the availability of heavy metal pollution control measures, this technique has been widely adopted.

Previous reports revealed that heavy metal primarily accumulated in fine fractions of soil (Cai et al., 2015). However, studies of the relationship of heavy metal content, fraction and PS in river sediment are limited. Heavy metal soil remediation technologies did not distinguish PS due to the small PS range of soil. However, the river sediment, especially in mining areas, contained pebbles, coarse sand and fine sand. Considering that the size and surface structure could affect the adsorption and desorption of sediment and that the fraction could affect the migration and toxicity of heavy metals in sediment, it is feasible to carry out ectopic remediation for heavy metals within sediment based on size distribution.

The abundant gold resources in mining areas could significantly promote local economic development, but long-term and macroscopic mining has resulted in adverse effects on the local environment. The discharge of smelting wastewater and leached filtrate of ore and slag have caused serious and extensive heavy metal pollution of water bodies and river sediments. Ex situ remediation may be a suitable method to remove heavy metals for river sediment remediation. However, the traditional ectopic treatment method is sanitary landfill, which is costly and wasteful to limited land. Therefore, this study attempts to find a feasible and economic method for heavy metal contaminated sediment remediation based on PS.

The objectives of this study were (1) to investigate the distribution and mobilization potential of heavy metals through PS in the river sediment in a mining area; (2) to develop a multistep remediation technology for heavy metal contaminated sediment based on PS; and (3) to verify the feasibility and sustainability by field engineering.

\section{Materials and methods}

\subsection{Study area description and sample collection}

Jiehe River locates in the biggest gold mining and smelting industrial zones in China (Fig. 1). In recent decades, numerous artisanal gold mines employed the rudimentary amalgamation technologies in the extraction process. Therefore, corresponding inexpensive heavy metals such as $\mathrm{Cu}, \mathrm{Zn}, \mathrm{Cd}$, As and $\mathrm{Hg}$ were discharged with tailing during the gold separation process. In the rainy season, some tailing (fine sand) would be transported to the Jiehe River, resulting in heavy metal pollution in sediments (Cai et al., $2015,2017)$. In this study, a detailed investigation of heavy metal pollution was carried out in the Jiehe River from $37.418325^{\circ} \mathrm{N}$, $120.384643^{\circ} \mathrm{E}$ to $37.498833^{\circ} \mathrm{N}, 120.294722^{\circ} \mathrm{E}$. The total length was $11.74 \mathrm{~km}$.

Sediments in a typical location with high heavy metal content were collected for laboratory testing; the detailed location was shown in Supplemental Fig. S1. The depth of sampling in this study was $0.5 \mathrm{~m}$ by auger drilling, and samples were stored in clean polyethylene bags (discharged air) and brought back to the laboratory within $4 \mathrm{~h}$. The plant rhizome, stone, brick and nubby domestic garbage in samples were eliminated prior to cold drying by a vacuum freeze dryer. Rocks in sediment were removed through a 4 mesh $(4.75 \mathrm{~mm})$ sieve and separated for later use as building materials. The screened sample was stored in a clean plastic bag and referred to as "raw sediment".

\subsection{Determination methods}

\subsubsection{Chemical washing experiments}

Approximately $100 \mathrm{~g}$ of raw sediment samples were placed in $1000 \mathrm{~mL}$ beakers, then $500 \mathrm{~mL}$ Mili-Q water (control) and given concentration washing agents (e.g. EDTA, citric acid) were added into each of the above beakers. The washing experiment was performed using a six-unit agitator at room temperature. Stirring speed and time were set at $800 \mathrm{r} \mathrm{min}^{-1}$ and $60 \mathrm{~min}$, respectively.

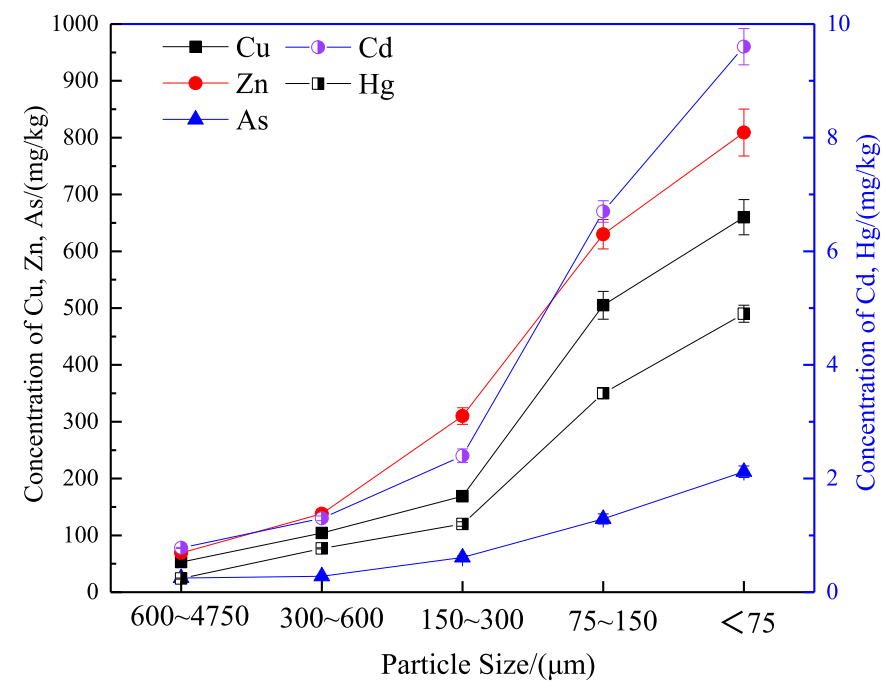

Fig. 1. Concentration of heavy metals in various particle size fractions. 
After agitation, the solid-liquid separation was performed by filtration $(0.45 \mu \mathrm{m})$. After filtration, size classification and heavy metal determination were conducted.

\subsubsection{PS classification}

Based on the theory of granularity and application in construction industry, reasonable gradation can save cement and guarantee the workability, durability and pumpability of concrete. The common fineness moduli were 4750, 2360, 1180, 600, 300, and $150 \mu \mathrm{m}$ based on China standard of "Pebble and crushed stone for construction" (GBT14865-2011) so that the particle sediments can be recycled directly after remediation. In the PS classification test, the fineness moduli were adjusted to $4750,600,300,150$, and $75 \mu \mathrm{m}$ based on China standard of "Sand for construction" (GBT14864-2011) for its potential application after remediation. A certain amount of raw sediments were placed in a mortar for manual grinding (to break the block of sediment) and were screened by a high frequency vibrating screen. Apertures of the vibrating screen mesh decreased from top to bottom as follows: 30 mesh, 50 mesh, 100 mesh and 200 mesh, corresponding to mesh diameters of $600,300,150$ and $75 \mu \mathrm{m}$, respectively. After shaking for $2 \mathrm{~h}$, the sediments that remained on the sieve and that passed through the sieve were collected and weighed for corresponding further analysis.

\subsubsection{Total heavy metal content and fractionations}

The raw and sieved sediments $(0.2500 \mathrm{~g} \pm 0.0001)$ were transferred into Teflon tubes, and were digested with a mixed solution of $\mathrm{HNO}_{3}+\mathrm{HF}+\mathrm{HClO}_{4}(8: 5: 2, \mathrm{v} / \mathrm{v})$ in a microwave digestion instrument (Tank Basic, Sineo Microwave Chemistry Technology Co., LTD, China). The concentrations of $\mathrm{Cu}, \mathrm{Zn}, \mathrm{Cd}$, As and $\mathrm{Hg}$ were determined by inductively coupled plasma mass spectrometry (ICP-MS, PerkinElmer NexlON 300Q USA). The fractions of heavy metals in sediments (raw and sieved sediments) were determined by the three-step continuous extraction method - BCR (Pueyo, 2001). The heavy metal fractions were divided into four parts: weak acid extractable fraction (interchangeable fraction and carbonate bound), reducible fraction (ferro-manganese oxide bound), oxidizable fraction (organics and sulfide bound) and residual fraction.

\subsubsection{Stabilization experiments}

Based on pre-experiments, sediments with PS $<300 \mu \mathrm{m}$ were selected for the stabilization experiment. Stabilizers (sodium sulfide, sodium thiosulfate, bentonite and dithiocarbamate type chelating resin (DTCR, Hou et al., 2012)) were added with the following proportions: $4 \%, 6 \%, 8 \%, 12 \%$ and $16 \%$ of total sample mass, respectively, and with the following dose proportions: $10 \%, 20 \%$, $30 \%, 40 \%$ and $50 \%$ of the dose of Portland cement to make the sediment to be solidified based on the results of pre-experiments. The detailed stabilization experiment was as follows: the mixtures were stirred for $30 \mathrm{~min}$, then placed into an incubator for 7 days. After stabilization, the concentrations of heavy metals in the leaching liquid and the sequentially extracted fractions in the residual sediment were determined to observe potential fraction transformation after stabilization.

In China, National Standards such as HJ/T 299-2007 and HJ/T 300-2007 have been applied in the literature to assess the leaching toxicity of sediment (Xiao et al., 2018). The tests of leachability and mobility in this work were assessed according to the above standards. Before and after solidification, $2 \mathrm{~g}$ sediment samples were freeze dried, then $40 \mathrm{~mL}$ extraction solution ( $\mathrm{pH} 2.64$ ) was prepared by diluting $17.25 \mathrm{~mL} \mathrm{CH} \mathrm{CH}_{3} \mathrm{COOH}$ with $1 \mathrm{~L}$ deionized water. Subsequently, the sediment samples before and after solidification and the extraction solution were placed into a $50 \mathrm{~mL}$ PE centrifuge tube, respectively, and vibrated at $30 \mathrm{rpm}$ and $25^{\circ} \mathrm{C}$ for $18 \mathrm{~h}$ in an oscillator. The extract was filtered into a $100 \mathrm{~mL}$ flask by a $0.45 \mu \mathrm{m}$ pore size syringe filter, and then acidified by nitric acid to $\mathrm{pH}<2$. The concentrations of targeted potentially toxic metals in the resulting filtrate were measured using ICP-OES (Liu et al., 2016; Wang et al., 2015; Zhou et al., 2013), then compared to guideline values with their thresholds in GB 5085.3-2007 (China standard of "Identification standards for hazardous wastes-Identification for extraction toxicity"). Afterwards, the leaching toxicity was performed base on the procedures of Solid waste-Extraction procedure for leaching toxicity- Sulphuric acid \& nitric acid method (China standard, HJ/T 299-2007) and Solid waste-Extraction procedure for leaching toxicity- Acetic acid buffer method (HJ/T 300-2007), and all results are summarized in Supplemental Table S1.

The stabilization efficiency of heavy metals was calculated by the following equation.

$\eta=\frac{C_{0}-C_{s}}{C_{0}} \times 100 \%$

where $\eta$ is stabilization efficiency (\%); $C_{0}$ and $C_{s}$ are the concentrations of heavy metal in the leaching solution of the sediment before and after stabilization treatment. The comprehensive stabilization efficiency of sediment is characterized by the average value of all heavy metals analyzed within the sediment.

\subsection{Field engineering}

The field engineering was carried out in the Jiehe River. The engineering strategies primarily included dredging, treatment and disposal of heavily polluted sediment. Total treated river length was approximately $6 \mathrm{~km}$. The dredging capacity was $145,000 \mathrm{~m}^{3}$ with percentage of water content $\sim 80 \%$. Arsenic, $\mathrm{Cu}, \mathrm{Zn}, \mathrm{Cd}$ and $\mathrm{Hg}$ were selected as targeted heavy metals. Based on the calculation by average values, total removal of $\mathrm{As}, \mathrm{Cu}, \mathrm{Zn}, \mathrm{Cd}$ and $\mathrm{Hg}$ were $1.48 \mathrm{t}$, $63.25 \mathrm{t}, 55.74 \mathrm{t}, 0.58 \mathrm{t}$ and $0.44 \mathrm{t}$, respectively.

According to the temporal sequence for potential reclaim as construction material, the technological process was divided into seven parts: sundries cleaning, sediment dredging, sediment screening (including leaching), mud dehydration and capacity reduction, stabilization-solidification, tail water treatment and temporary site ecological restoration.

\section{Results and discussion}

\subsection{Correlation between PS and total heavy metal content}

The characteristics of sediment PS are controlled by the geological conditions of the river and are also influenced by the provenance characteristics, petrography of source rocks, transport medium, hydrodynamic strength and transport mode, as well as urban human activities and biological factors. The PS distribution of sediment is shown in Supplemental Fig. S2. The proportions of sediment fractions with PS $<75 \mu \mathrm{m}, 75-150 \mu \mathrm{m}, 150-300 \mu \mathrm{m}$, $300-600 \mu \mathrm{m}$ and $600-4750 \mu \mathrm{m}$ were $2.4 \%, 6.47 \%, 13.03 \%, 19.12 \%$ and $58.98 \%$, respectively. The sizes of most sediment particles were greater than $150 \mu \mathrm{m}$, accounting for $91 \%$ of the total. Therefore, the river sediment was sandy.

The total concentrations of $\mathrm{Zn}, \mathrm{Cu}, \mathrm{Cd}, \mathrm{Hg}$ and $\mathrm{As}$ in various PS fractions of sediments are illustrated in Fig. 1. The results show that the highest concentrations of the five heavy metals appeared in the portion of PS $<75 \mu \mathrm{m}$ fraction, and the lowest appeared in the large particle fraction $(600<\mathrm{PS}<4750 \mu \mathrm{m})$. Thus, most metals are contained in fine sediment. Overall, the concentration of heavy metals in sediment gradually decreased with increasing PS, presenting an 


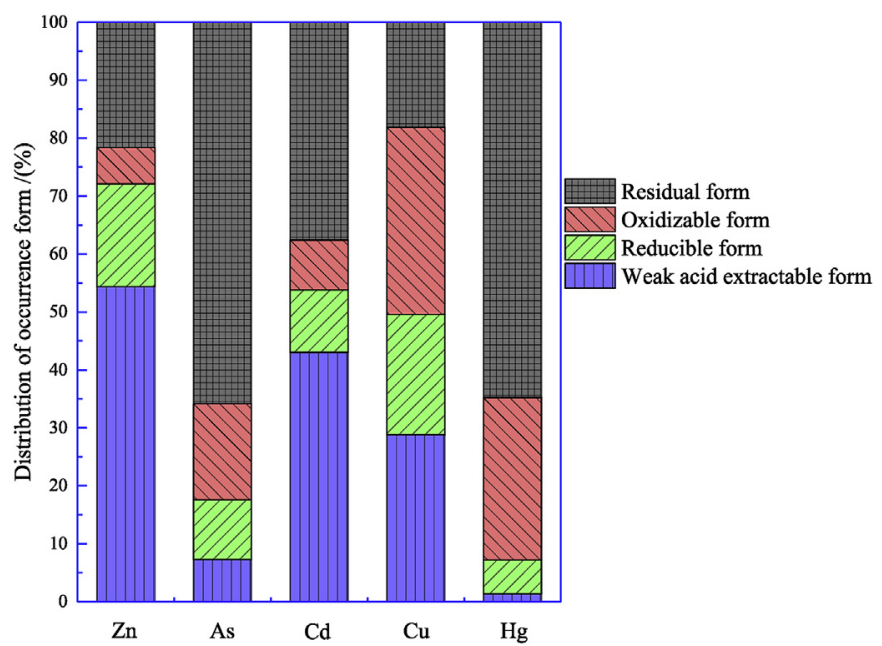

Fig. 2. Sequentially extracted fraction distribution of heavy metals in raw sediment. obvious "PS effect".

The "PS effect" of heavy metal distribution is the result of multiple physical and chemical factors (Loska and Wiechuła, 2003; Unda-Calvo et al., 2019). There is abundance of quartz (reflected by $\mathrm{SiO} 2$ ) in sediments with larger grains and low adsorption capacity, exerting a "dilution effect" on other metals in sediments. However, fine-grained sediments and the clay minerals have higher superficial area and surface activity, resulting in strong adsorption for heavy metals (Roussiez et al., 2005).

\subsection{Correlation between PS and heavy metal forms}

The sequentially extracted fractions of five heavy metals in raw sediment are shown in Fig. 2. It can be observed that the fraction significant differed between various metals. The main sequentially extracted fraction of $\mathrm{Zn}$ was the weak acid extractable form, a fraction with poor stability and high environmental risk that could be released under the circumstance of acidic or neutral conditions. The dominant sequentially extracted fractions of As was the
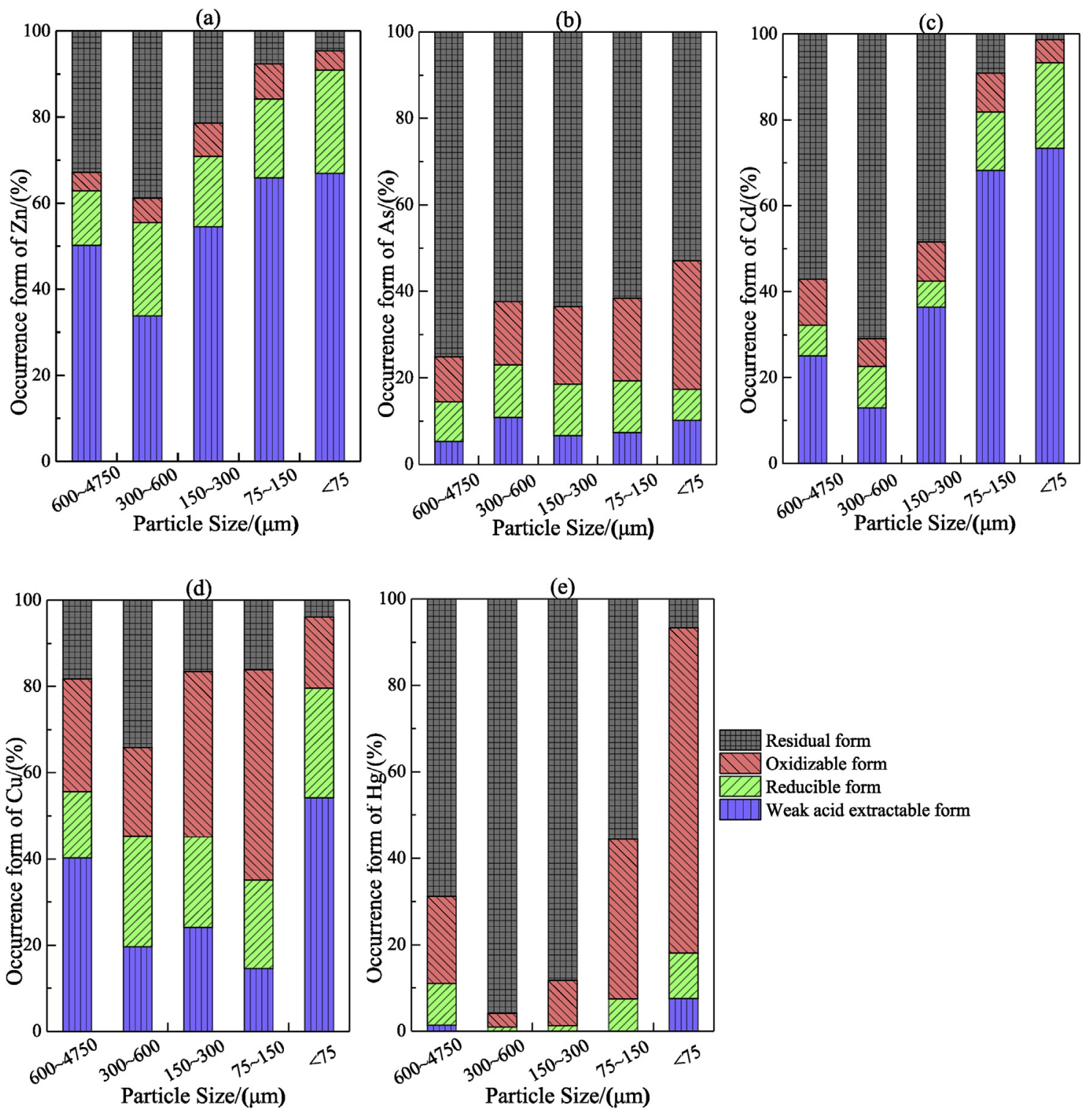

Fig. 3. Sequentially extracted fractions of heavy metals in various size fractions. 
residual form, which possesses the maximum stability and the lowest environmental risk. Copper was distributed in a relatively uniform fashion, with various types of sequentially extracted fractions of heavy metals, in which the acid extractable form and oxidizable form were more prevalent than others. The sequentially extracted fraction of $\mathrm{Cd}$ was mainly composed of the weak acid extractable form and residual form, while the main sequentially extracted fractions of $\mathrm{Hg}$ were residual fraction and oxidizable fraction. The oxidizable fraction metals were relatively stable; but could be mobilized under the condition of strong oxidation. The reducible $\mathrm{Cu}$ presented excellent bioavailability: it was easily released when the redox potential of water decreased or water was depleted of oxygen.

Heavy metal fraction in various PS fractions of raw sediment is shown in Fig. 3. The results showed that the proportion of the mobile fractions of five heavy metals gradually increased and the proportion of the residual fraction gradually decreased with PS decrease, except in the case of the large size fraction $(600 \mu \mathrm{m}<\mathrm{PS}<4750 \mu \mathrm{m})$. This phenomenon indicated that small PS components $(<75 \mu \mathrm{m})$ not only contained the highest concentration of total heavy metals but also posed the highest ecological hazard. In contrast, the lowest heavy metal content and the lowest
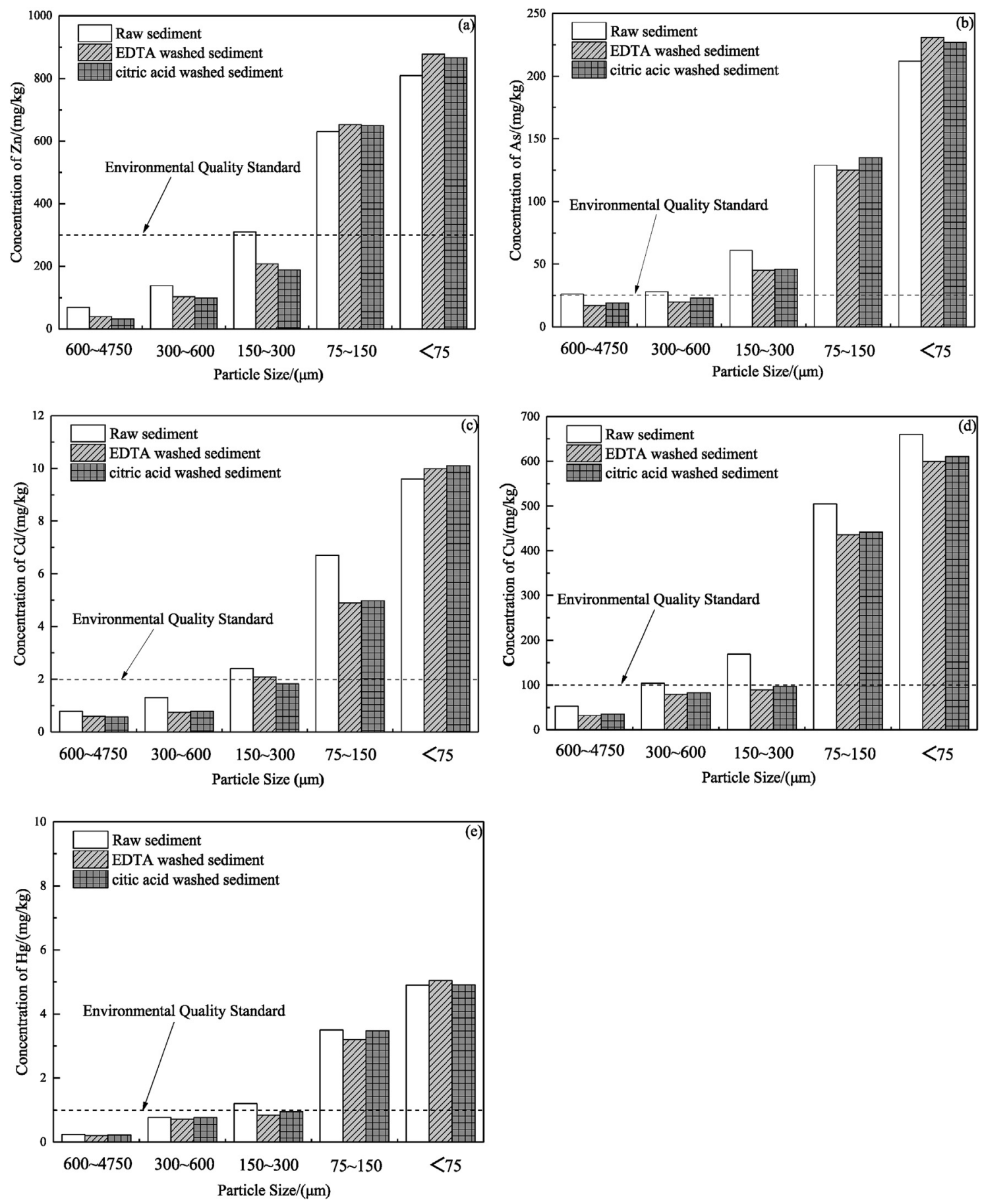

Fig. 4. Heavy metals in various fractions of raw sediment and after leaching. 
ecological toxicity were presented in the large PS components $(>300 \mu \mathrm{m})$. Therefore, for the remediation of heavy metal contaminated sediment within rivers in mining regions, the attention should be focused on the small PS components $(<75 \mu \mathrm{m})$.

Based on the distribution and the sequentially extracted fractions of heavy metals with PS, the classification treatment and recovery technique of heavy metal contaminated sediment was proposed. By means of this attempt, the slightly polluted sediments with large PS could be separated from heavily polluted sediment with small PS. Furthermore, heavy metals deposited in large PS components could be washed into the liquid phase by chemical leaching, and then the clean large PS components in sediment could be used as building materials directly, producing economic interest to realize sustainable engineering strategy. The heavily
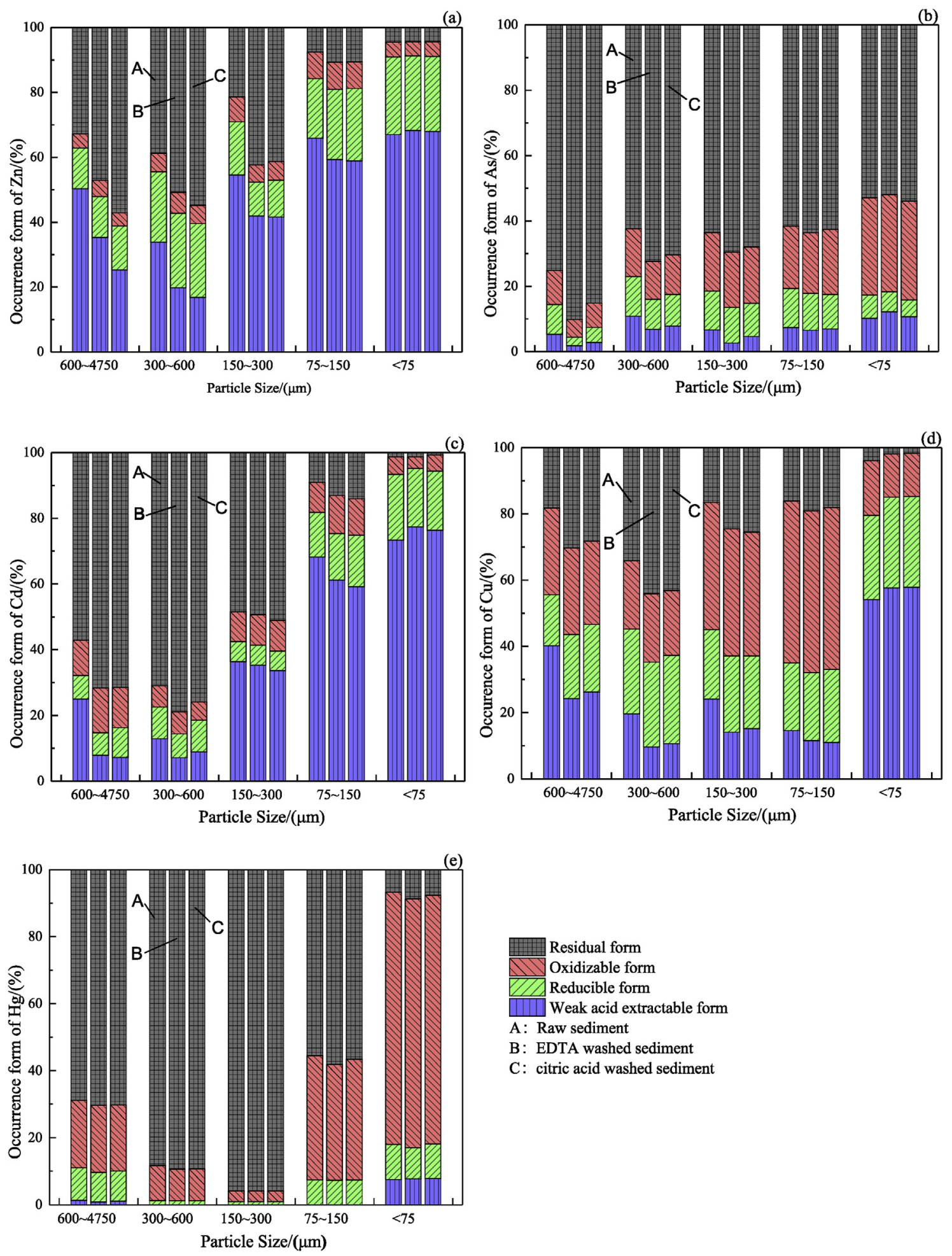

Fig. 5. Sequentially extracted fractions of heavy metals in various size fractions of raw sediment and after leaching. 
polluted sediment with small PS could be buried as general industrial solid waste after stabilization treatment.

\subsection{Chemical washing}

The sediments washed by EDTA and citric acid were screened to five PS fractions: $(600-4750 \mu \mathrm{m}, 300-600 \mu \mathrm{m}, 150-300 \mu \mathrm{m}$, $75-150 \mu \mathrm{m}$ and $<75 \mu \mathrm{m})$. The changes of concentrations and sequentially extracted fractions of five heavy metals in various size fractions after chemical washing are shown in Fig. 4 and Fig. 5. The corresponding environmental quality standard was determined by referring to specific representative standards and local soil background values comprehensively (Supplemental Table S2).

In the raw sediments (untreated), the total contents of all metals in the PS $<300 \mu \mathrm{m}$ components were substandard, Cu was up to the standard only with respect to the PS $>600 \mu \mathrm{m}$ components, and As was substandard in all components. However, the situation changed after EDTA washing. $\mathrm{Zn}, \mathrm{Cu}$, and $\mathrm{Hg}$ in the PS $>150 \mu \mathrm{m}$ components and As and Cd in the PS $>300 \mu \mathrm{m}$ components all reached the standard. Similarly, after citric acid washing, $\mathrm{Zn}, \mathrm{Cd}, \mathrm{Cu}$, and $\mathrm{Hg}$ in the PS $>150 \mu \mathrm{m}$ components and As in the PS $>300 \mu \mathrm{m}$ components all met the standard. These results indicate that chemical washing could efficiently remove heavy metals, especially the heavy metals in the large PS components of sediment.

As shown in Fig. 4, EDTA and citric acid demonstrated a similar trend for heavy metal removal: heavy metals in large PS components decreased after washing, while in small PS components, heavy metal increased. Therefore, this finding suggested that the small PS sediment trapped metals from the large PS sediment during the leaching process because of the combined action of hydrodynamic shear force and physical friction force; the unstable heavy metals on large PS sediment were washed into solution phase and recombined with small particle sediment, which exhibited stronger adsorption to heavy metals. As a result, a fraction of the heavy metals were transferred to small size sediment after chemical washing.

Fig. 5 exhibited the change of sequentially extracted fractions of five heavy metals in various size fractions after chemical washing. It can be observed that EDTA and citric acid washing could significantly reduce the proportion of unstable heavy metals with PS $>75 \mu \mathrm{m}$, except in the case of $\mathrm{Hg}$. Generally, sodium metal ions in EDTA have a metathesis effect on heavy metals. Meanwhile, as a chelating agent, EDTA could combine with some heavy metals adsorbed in soil, especially ferromanganese oxides, and form stable complexes through complexation (Sun et al., 2001). The removal of heavy metals by citric acid was dependent on the effect of acidity
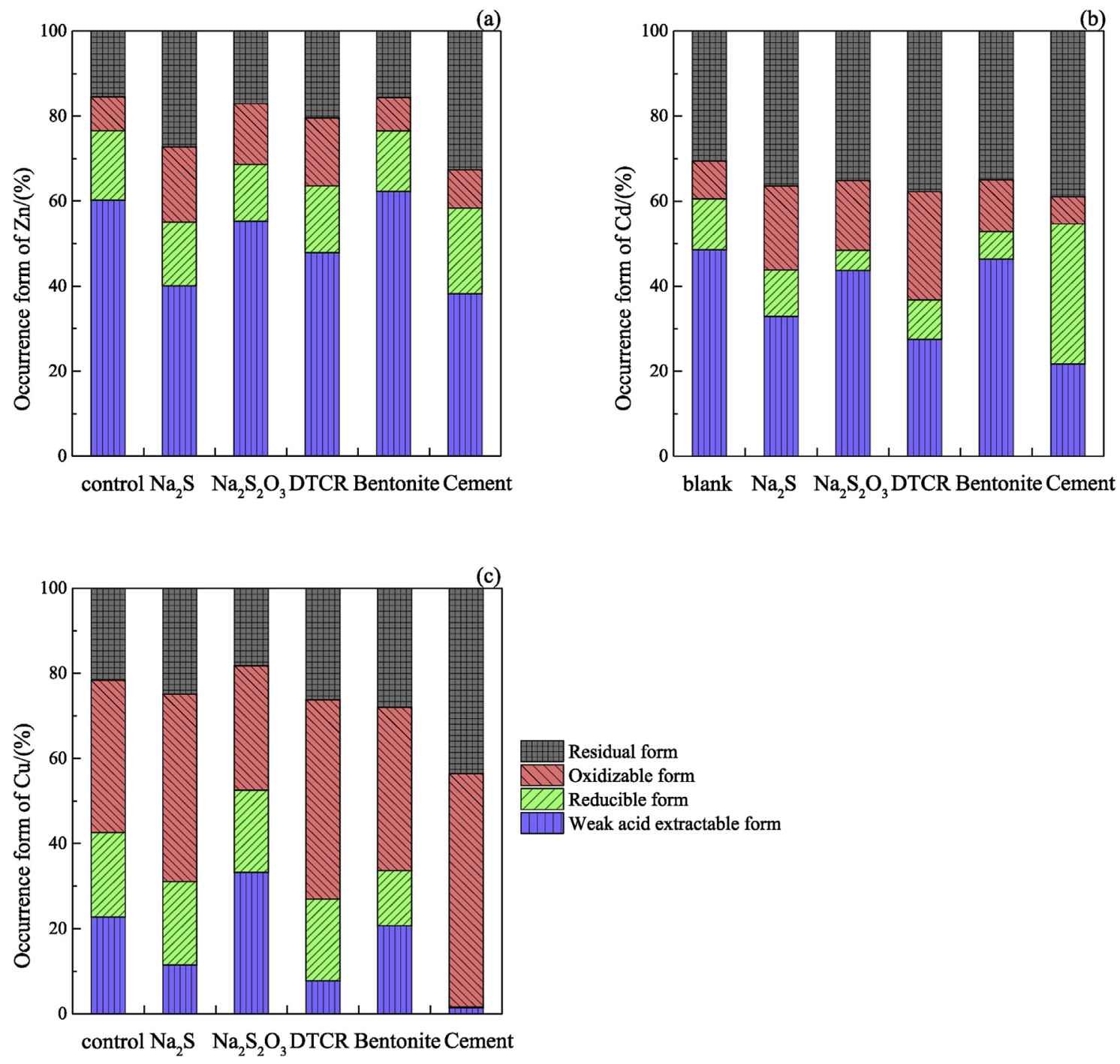

Fig. 6. Effects of stabilizers on the sequentially extracted fractions of heavy metals. 
Table 1

Lixiviating amount and lixiviating rate of heavy metal in small size sediment.

\begin{tabular}{lll}
\hline Heavy metals & Lixiviating amount/ $(\mathrm{mg} / \mathrm{kg})$ & Lixiviating rate $/(\%)$ \\
\hline $\mathrm{Zn}$ & 98.73 & 21.50 \\
$\mathrm{As}$ & 1.953 & 2.00 \\
$\mathrm{Cd}$ & 0.606 & 13.60 \\
$\mathrm{Cu}$ & 50.89 & 15.80 \\
$\mathrm{Hg}$ & 0.045 & 1.98 \\
\hline
\end{tabular}

on the dissolution of heavy metals and the competitive adsorption of heavy metals by EDTA or other organic compounds and sediment particles. Therefore, after chemical washing, the proportion of nonresidual fraction heavy metals in small size sediment with PS $<75 \mu \mathrm{m}$ hardly changed. This hypothesis was proven and confirmed by the results in Fig. 6: the unstable heavy metals in large PS sediment were washed into the water phase and reattached to small PS sediment. Therefore, chemical washing treatment could effectively reduce the total heavy metal and unsteady fraction proportion of large PS sediment and subsequently reduce the ecological toxicity. At the same time, the concentration of heavy metals, especially the unstable heavy metals in small PS sediment, increased. Overall, chemical washing concentrated heavy metals in small PS sediment, which required stabilization treatment due to its high release risk and leaching toxicity.

\subsection{Stabilization treatment for small PS sediment}

Table 1 exhibited the heavy metal lixiviating amounts and lixiviating rates of small PS sediment samples (PS $<300 \mu \mathrm{m})$. As seen from Table $1, \mathrm{Zn}$ exhibited the largest lixiviating rate (21.50\%), while $\mathrm{Hg}$ had the smallest lixiviating rate (1.98\%), which is related to heavy metal properties such as fraction distribution. The stabilization study of heavy metals was not conducted for As because its lixiviating rates were low in pre-experiments (close to zero). The $\mathrm{pH}$ value of the sediment was 7.5, and the effect of adding different stabilizers on the $\mathrm{pH}$ value of the sediment was shown in Supplemental Table S3.
The stabilization efficiency of different stabilizers for heavy metals is shown in Table 2. It can be seen that all stabilizers exerted a significant stabilizing effect on heavy metals, and the stability efficiency increased with the dosage increase. The stabilizers with the highest stability rate for $\mathrm{Zn}$ and $\mathrm{Cd}$ were cement, with stable efficiency values of $90.02-96.73 \%$ and $77.35-86.92 \%$, respectively, while the choice for $\mathrm{Cu}$ was bentonite with the stable efficiency of 87.37-90.23\%. According to the comprehensive stability efficiency for three heavy metals, the five stabilizers could be listed in the following order: cement $>$ bentonite $>$ DTCR $>\mathrm{Na}_{2} \mathrm{~S}>\mathrm{Na}_{2} \mathrm{~S}_{2} \mathrm{O}_{3}$. It was obvious that the stability effect of cement with the heavy metal wrapping mechanism was better than that of bentonite and sodium sulfide with chemical reaction as the stability mechanism, because the Portland cement has strong adsorption for its hydrated calcium silicate $(\mathrm{C}-\mathrm{S}-\mathrm{H})$ structure, high internal surface and pore structure (Niu et al., 2018). This is because the sealing effect of stabilizers on heavy metals can transform the heavy metal form the soluble to insoluble state, slowing its dissolution rate; the effect of chemical reaction is that heavy metals will be released back into the environment when the environment changes.

Sequentially extracted fraction distributions of heavy metals were analyzed for the sediments with the maximum dosage of stabilizers, and the analysis results are shown in Fig. 6. In Fig. 6, cement, DTCR and $\mathrm{Na}_{2} \mathrm{~S}$ could effectively reduce the proportion of weak acid extractable form of three heavy metals and simultaneously increase the proportion of residual form. However, the effect of bentonite on the sequentially extracted fractions of heavy metal was weak, which was related to its stabilization mechanism (ion exchange). This is consistent with the conclusion in Fig. 5 that the lixiviating amounts of heavy metals were positively correlated with the contents of weak acid extractable form. The substandard small PS sediment could achieve harmless disposal after stabilization treatment.

\subsection{Application in field engineering}

Based on the above results, a method for the treatment of heavy

Table 2

Stability efficiency of various stabilizers for heavy metal.

\begin{tabular}{|c|c|c|c|c|c|}
\hline \multirow[t]{2}{*}{ Stabilizers } & \multirow[t]{2}{*}{ Dose proportion/(\%) } & \multicolumn{4}{|c|}{ Stability efficiency/ (\%) } \\
\hline & & $\mathrm{Zn}$ & $\mathrm{Cd}$ & $\mathrm{Cu}$ & Average level \\
\hline \multirow[t]{5}{*}{$\mathrm{Na}_{2} \mathrm{~S}$} & 4 & 79.94 & 64.61 & 65.18 & 69.91 \\
\hline & 6 & 83.18 & 68.38 & 80.83 & 77.46 \\
\hline & 8 & 92.86 & 71.25 & 82.55 & 82.22 \\
\hline & 12 & 93.86 & 73.86 & 84.76 & 84.16 \\
\hline & 16 & 94.92 & 76.32 & 85.29 & 85.51 \\
\hline \multirow[t]{5}{*}{$\mathrm{Na}_{2} \mathrm{~S}_{2} \mathrm{O}_{3}$} & 4 & 66.12 & 41.29 & 39.52 & 48.98 \\
\hline & 6 & 73.89 & 52.39 & 63.18 & 63.15 \\
\hline & 8 & 80.11 & 54.27 & 71.44 & 68.61 \\
\hline & 12 & 82.77 & 61.63 & 75.92 & 73.44 \\
\hline & 16 & 84.41 & 79.36 & 74.81 & 79.53 \\
\hline \multirow[t]{5}{*}{ DTCR (Dithiocarbamate type chelating resin) } & 4 & 80.76 & 70.31 & 82.21 & 77.76 \\
\hline & 6 & 82.03 & 72.80 & 82.79 & 79.21 \\
\hline & 8 & 82.94 & 73.25 & 81.37 & 79.19 \\
\hline & 12 & 83.47 & 75.92 & 84.28 & 81.22 \\
\hline & 16 & 92.32 & 78.16 & 82.63 & 84.37 \\
\hline \multirow[t]{5}{*}{ Bentonite } & 4 & 81.48 & 72.37 & 87.37 & 80.41 \\
\hline & 6 & 83.06 & 74.16 & 86.91 & 81.38 \\
\hline & 8 & 84.45 & 73.91 & 88.04 & 82.13 \\
\hline & 12 & 92.29 & 75.47 & 89.26 & 85.67 \\
\hline & 16 & 95.49 & 77.44 & 90.23 & 87.72 \\
\hline \multirow[t]{5}{*}{ Cement } & 10 & 90.02 & 77.35 & 76.38 & 81.25 \\
\hline & 20 & 90.82 & 79.61 & 78.38 & 82.94 \\
\hline & 30 & 91.75 & 80.36 & 79.45 & 83.85 \\
\hline & 40 & 95.30 & 83.72 & 82.69 & 87.24 \\
\hline & 50 & 96.73 & 86.92 & 88.13 & 90.59 \\
\hline
\end{tabular}




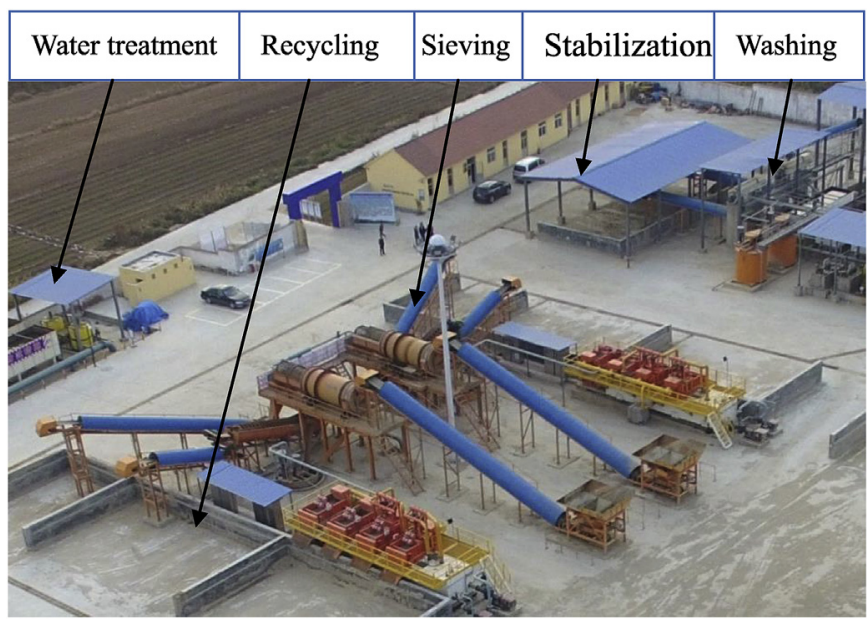

Fig. 7. Aerial view of the site of the demonstration project

metal pollution in sandy river sediment was developed, and a set of multistage automatic screening leaching equipment was assembled. The multistage automatic screening and leaching equipment was composed of roller stone washing machine, screw sand washing machine, multistage high frequency vibrating screen, flocculation pool, centrifuge and stable solidification machine (Supplemental Fig. S3). The leaching agent was added to the "regulating pool" after the screw sand washing machine, and the stabilizer was added to the charging pool before the centrifuge. Through multistage screening, the sediment could be screened to five PS fractions: $>4.75 \mathrm{~mm}, 1.18-4.75 \mathrm{~mm}, 0.3-1.18 \mathrm{~mm}$, $0.075-0.3 \mathrm{~mm}$ and $<0.075 \mathrm{~mm}$. After leaching and screening, the qualified sediment was used as building material, and the substandard parts were buried. Parameters such as PS range, type and dosage of eluent and stabilizer, solid-liquid ratio and residence time were adjusted according to the physical and chemical properties of the actual sediment, the distribution characteristics (equilibria) of heavy metals and the sequentially extracted fractions of heavy metals to maximize the treatment efficiency.

After several medium trials and technological modifications, the process was applied to heavy metal contaminated sediment treatment and ecological restoration demonstration projects in Jiehe River (Fig. 7). In the project, the backfilling amounts of recycling pebbles, gravel and sand were approximately $9.3 \times 10^{4} \mathrm{~m}^{3}$, accounting for approximately $64 \%$ of the total excavation amount; approximately $10 \%$ of total treated sediment was used as general building material; approximately $13 \%$ was buried as general industrial solid, and at the same time, the last $13 \%$ was taken to final disposal.

The implementation of this project effectively achieved the separation of the heavy metal-rich components and clean components, as well as the separation of various clean sediments, by using different functions. Compared to traditional treatment technology, the final disposal amount of the contaminated sediment was greatly reduced, while the proportion of the recycling exploitable sediment was improved significantly. The project was of great significance for improving water environment quality, safeguarding human health and ensuring environmental safety, which created significant environmental and socioeconomic benefits.

\section{Conclusions}

(1) The distribution of heavy metals in mining area river sediment showed significant "PS effect": small PS components have a higher heavy metal concentration and a larger proportion of non-residual fraction, which leads to high ecotoxicity.

(2) Some heavy metals, especially in the non-residual fraction, were transferred to the small PS sediment after chemical washing; this allowed the large PS components in the sediment to reach the standards for use as building materials.

(3) Heavy metals in small PS components could be stabilized by cement and other materials, which reduces the lixiviating toxicity and reduces risk in order to achieve the harmless disposal of heavy metal contaminated sediment.

(4) The application of the classification treatment of heavy metal contaminated sediment based on PS distribution in the Jiehe River proved the feasibility of the technology.

\section{Acknowledgments}

This study was supported by the Strategic Priority Research Program of the Chinese Academy of Sciences (Grant No.: XDA23050203) and the National Natural Science Foundation of China (Grant No. 41373100). Additional support was provided by the CAS Key Technology Talent Program and the Instrument Developing Project of the Chinese Academy of Sciences (Grant No.Y728021021).

\section{Appendix A. Supplementary data}

Supplementary data related to this article can be found at https://doi.org/10.1016/j.chemosphere.2019.03.018.

\section{References}

Begum, Z.A., Rahman, I.M., Tate, Y., Sawai, H., Maki, T., Hasegawa, H., 2012. Remediation of toxic metal contaminated soil by washing with biodegradable aminopolycarboxylate chelants. Chemosphere 87, 1161-1170. https://doi.org/10. 1016/j.chemosphere.2012.02.032.

Cai, L., Xu, Z., Bao, P., He, M., Dou, L., Chen, L., Zhou, Y., Zhu, Y.G., 2015. Multivariate and geostatistical analyses of the spatial distribution and source of arsenic and heavy metals in the agricultural soils in Shunde, Southeast China. J. Geochem. Explor. 148, 189-195. https://doi.org/10.1016/j.gexplo.2014.09.010.

Cai, Y., Zhang, H., Yuan, G., Li, F., 2017. Sources, speciation and transformation of arsenic in the gold mining impacted Jiehe River, China. Appl. Geochem. 84, 254-261. https://doi.org/10.1016/j.apgeochem.2017.07.001.

Chowdhury, S., Mazumder, M.A.J. Al-Attas, O., Husain, T, 2016. Heavy metals in drinking water: Occurrences, implications, and future needs in developing countries. Sci. Total Environ. 569-570, 476-488. https://doi.org/10.1016/j. scitotenv.2016.06.166.

Goretti, E., Pallottini, M., Ricciarini, M.I., Selvaggi, R., Cappelletti, D., 2016. Heavy metals bioaccumulation in selected tissues of red swamp crayfish: an easy tool for monitoring environmental contamination levels. Sci. Total Environ. 559, 339-346. https://doi.org/10.1016/j.scitotenv.2016.03.169.

Hou, J., Lu, R., Sun, M., Baig, S.A., Tang, T., Cheng, L., Xu, X., 2012. Effect of heavy metals on the stabilization of mercury(II) by DTCR in desulfurization solutions. J. Hazard Mater. 217-218, 224-230. https://doi.org/10.1016/j.jhazmat.2012.03. 016.

Khan, F.I., Husain, T., Hejazi, R., 2004. An overview and analysis of site remediation technologies. J. Environ. Manag. 71, 95-122. https://doi.org/10.1016/j.jenvman. 2004.02.003.

Li, Y., Liao, X., Li, W., 2019. Combined sieving and washing of multi-metalcontaminated soils using remediation equipment: a pilot-scale demonstration. J. Clean. Prod. 212, 81-89. https://doi.org/10.1016/j.jclepro.2018.11.294.

Lin, Y., Meng, F., Du, Y., Tan, Y., 2016. Distribution, speciation, and ecological risk assessment of heavy metals in surface sediments of Jiaozhou Bay, China. Human and Ecological Risk Assessment. Int. J. 22, 1253-1267. https://doi.org/10.1080/ 10807039.2016.1159503.

Liu, B., Li, J., Zeng, Y., Wang, Z., 2016. Toxicity assessment and geochemical model of chromium leaching from AOD slag. Chemosphere 144, 2052-2057. https://doi. org/10.1016/j.chemosphere.2015.10.103.

Liu, L., Li, W., Song, W., Guo, M., 2018a. Remediation techniques for heavy metalcontaminated soils: Principles and applicability. Sci. Total Environ. 633, 206-219. https://doi.org/10.1016/j.scitotenv.2018.03.161.

Liu, S.J., Liu, Y.G., Tan, X.F., Zeng, G.M., Zhou, Y.H., Liu, S.B., Yin, Z.H., Jiang, L.H., Li, M.F., Wen, J., 2018b. The effect of several activated biochars on Cd immobilization and microbial community composition during in-situ remediation of heavy metal contaminated sediment. Chemosphere 208, 655-664. https://doi. 
org/10.1016/j.chemosphere.2018.06.023.

Loska, K., Wiechuła, D., 2003. Application of principal component analysis for the estimation of source of heavy metal contamination in surface sediments from the Rybnik Reservoir. Chemosphere 51, 723-733. https://doi.org/10.1016/ S0045-6535(03)00187-5.

Niu, M., Li, G., Wang, Y., Li, Q., Song, Z., 2018. Comparative study of immobilization and mechanical properties of sulfoaluminate cement and ordinary Portland cement with different heavy metals. Constr. Build. Mater. 193, 332-343. https:// doi.org/10.1016/j.conbuildmat.2018.10.206.

Polettini, A., Pomi, R., Rolle, E., Ceremigna, D., Tornato, A., 2006. A kinetic study of chelant-assisted remediation of contaminated dredged sediment. J. Hazard Mater. 137, 1458-1465. https://doi.org/10.1016/j.jhazmat.2006.04.022.

Pueyo, M., Rauret, G., Lück, D., Yli-Halla, M., Muntau, H., Quevauviller, P., LópezSánchez, J.F., 2001. Certification of the extractable contents of $\mathrm{Cd}, \mathrm{Cr}, \mathrm{Cu}, \mathrm{Ni}, \mathrm{Pb}$ and $\mathrm{Zn}$ in a freshwater sediment following a collaboratively tested and optimised three-step sequential extraction procedure. J. Environ. Monit. 3, 243-250. https://doi.org/10.1039/b010235k.

Roussiez, V., Ludwig, W., Probst, J.L., Monaco, A., 2005. Background levels of heavy metals in surficial sediments of the Gulf of Lions (NW Mediterranean): an approach based on 133Cs normalization and lead isotope measurements. Environ. Pollut. 138, 167-177. https://doi.org/10.1016/j.jhazmat.2006.04.022.

Sindern, S., Tremöhlen, M., Dsikowitzky, L., Gronen, L., Schwarzbauer, J., Siregar, T.H., Ariyani, F., Irianto, H.E., 2016. Heavy metals in river and coast sediments of the Jakarta Bay region (Indonesia) - geogenic versus anthropogenic sources. Mar Pollut. Bull. 110, 624-633. https://doi.org/10.1016/j.marpolbul.2016.06.003.

Song, B., Zeng, G., Gong, J., Zhang, P., Deng, J., Deng, C., Yan, J., Xu, P., Lai, C., Zhang, C. Cheng, M., 2017. Effect of multi-walled carbon nanotubes on phytotoxicity of sediments contaminated by phenanthrene and cadmium. Chemosphere 172, 449-458. https://doi.org/10.1016/j.chemosphere.2017.01.032.
Sun, B., Zhao, F.J., Lombi, E., McGrath, S.P., 2001. Leaching of heavy metals from contaminated soils using EDTA. Environ. Pollut. 113, 111-120. https://doi.org/10. 1016/S0269-7491(00)00176-7.

Unda-Calvo, J., Ruiz-Romera, E., de Vallejuelo, S.F.O., Martinez-Santos, M. Gredilla, A., 2019. Evaluating the role of particle size on urban environmenta geochemistry of metals in surface sediments. Sci. Total Environ. 646, 121-133. https://doi.org/10.1016/j.scitotenv.2018.07.172.

Villanueva, U., Raposo, J.C., Madariaga, J.M., 2013. A new methodological approach to assess the mobility of $\mathrm{As}, \mathrm{Cd}, \mathrm{Co}, \mathrm{Cr}, \mathrm{Cu}, \mathrm{Fe}, \mathrm{Ni}$ and $\mathrm{Pb}$ in river sediments. Microchem. J. 106, 107-120. https://doi.org/10.1016/j.microc.2012.05.031.

Wang, F.H., Zhang, F., Chen, Y.J., Gao, J., Zhao, B., 2015. A comparative study on the heavy metal solidification/stabilization performance of four chemical solidifying agents in municipal solid waste incineration fly ash. J. Hazard Mater. 300, 451-458. https://doi.org/10.1016/j.jhazmat.2015.07.037.

Xia, F., Qu, L., Wang, T., Luo, L., Chen, H., Dahlgren, R.A., Zhang, M., Mei, K., Huang, H. 2018. Distribution and source analysis of heavy metal pollutants in sediments of a rapid developing urban river system. Chemosphere 207, 218-228. https://doi. org/10.1016/j.chemosphere.2018.05.090.

Xiao, J., Zhang, L., Yuan, J., Yao, Z., Tang, L., Wang, Z., Zhang, Z., 2018. Co-utilization of spent pot-lining and coal gangue by hydrothermal acid-leaching method to prepare silicon carbide powder. J. Clean. Prod. 204, 848-860. https://doi.org/10. 1016/j.jclepro.2018.08.331.

Zhao, G., Ye, S., Yuan, H., Ding, X., Wang, J., 2017. Surface sediment properties and heavy metal pollution assessment in the Pearl River Estuary, China. Environ. Sci. Pollut. Res. 24, 2966-2979. https://doi.org/10.1007/s11356-016-8003-4.

Zhou, Y., Ning, X.A., Liao, X., Lin, M., Liu, J., Wang, J., 2013. Characterization and environmental risk assessment of heavy metals found in fly ashes from waste filter bags obtained from a Chinese steel plant. Ecotoxicol. Environ. Saf. 95, 130-136. https://doi.org/10.1016/j.ecoenv.2013.05.026. 